\title{
El linaje de los Canals, una familia catalana de los siglos XI-XIII
}

\author{
Juan José Cortés García \\ Universitat Autònoma de Barcelona. \\ Departament de Ciències de l'Antiguitat i de l'Edat Mitjana. \\ 08193. Bellaterra (Barcelona). Spain
}

\section{Resumen}

El autor presenta en su estudio la evolución de la familia Canals, a través de su estructura de parentesco. Las relaciones que establecerán con otros linajes del condado de Barcelona definirán su posición, tanto a nivel territorial como político y permitirán diferenciar los dos segmentos en que puede estructurarse esta familia, encabezados por Pere Guillem de Canals y por Ramon Guillem de Canals. El estudio se completa con un genograma y un apéndice con tres documentos fundamentales de la familia.

Durante las décadas de los setenta y ochenta la historiografia abrió sus puertas al atractivo $y$, a la vez, necesario estudio de las estructuras familiares de la sociedad medieval, $y$, en especial, al de las estructuras familiares feudales. Gracias a los descubrimientos de la antropología y en especial a los trabajos realizados por el profesor Georges Duby, numerosos historiadores incorporaron a su campo de investigación el estudio de las estructuras familiares. Por un lado, los trabajos procedían del campo teórico, donde habría que resaltar la obra de Jack Goody ${ }^{1}$, por el otro, veían la luz trabajos historiográficos que abordaban ese dificil campo de investigación de las costumbres de parentesco².

En Cataluña, los estudios de las estructuras de parentesco medieval fueron encabezados desde finales de los ańos setenta por el profesor José Enrique RuizDomènec. Durante los años ochenta aparecieron diversos estudios sobre linajes catalanes al filo del 1200 por John Schideler, Blanca Gari y por el propio Ruiz-Domènec ${ }^{3}$. En 1985 se produjo un punto de inflexión en el estudio de las estructuras familiares catalanas, iniciándose un abandono paulatino de este

1. Goody, J. (1983). The development of the family and marriage in Europe. Cambridge: University Press.

2. Gutchard, P. (1977). Structures sociales *orientales* et uoccidentales* dans IEspagne musulmane. Paris.

3. SCHIDELER, J. (1983). A Medival catalan Noble family. The Montcadas 1000-11230. Los Angeles; GaRI, B. (1985). El linaje de los Castellvell en los siglos X7 y XrI. Bellaterra. 
tipo de estudios, sólo roto por algunos artículos del profesor Ruiz-Domènec ${ }^{4}$ y por la lectura de la tesis de Maria Pont en $1987^{5}$, en la que aborda el estudio de las diferentes estructuras familiares barcelonesas del siglo XIII.

Diez años después, ese olvido ha sido subsanado por la obra del profesor de la Université de Poitiers, Martin Aurell ${ }^{6}$, con la publicación de una obra que se convertirá en punto de referencia obligado en la historiografía catalana de los próximos años.

Abordar el estudio de las estructuras familiares requiere introducirse en las relaciones que se establecieron entre los individuos de un determinado grupo; la documentación diplomática catalana, muy rica en cantidad, es en la mayoría de los casos poco específica y uniforme. El principal problema que se encuentra cualquier historiador de las estructuras familiares es la dispersión de los archivos familiares $y$, a veces, no sólo eso, sinó también la clausura de algunos de éstos.

El análisis de una familia catalana de los siglos XI-XIII no es tarea fácil, y no se resume únicamente en un genograma donde aparezcan la mayor parte de los miembros de esa familia. La familia Canals es una familia que remonta sus orígenes a finales del siglo XI, y que está estrechamente ligada al término del mismo nombre que está situado en el actual Valldoreix (Sant Cugat del Vallès). Para su estudio hemos consultado los fondos de cancillería del Archivo de la Corona de Aragón, así como el cartoral de Sant Cugat ${ }^{7}$ y el fondo de pergaminos del mismo monasterio. La familia Canals se encuentra situada territorialmente en las cercanías del monasterio de Sant Cugat, pero también en las zonas periféricas de la ciudad de Barcelona, como Montjǚc, Sta. Eulalia de Provençana, Sant Just, Sarrià, Sant Boi o Sant Feliu; ésto, unido a sus alianzas familiares y a su estructura de parentesco con las familias del ámbito barcelonés, nos conduce necesariamente a consultar el fondo documental de la catedral de Barcelona, $y$ en especial los volúmenes de los Libri Antiquitatum ${ }^{8}$.

Otras de las áreas de actividad de la familia Canals son el vizcondado de Cardona y en especial las zonas bajo la influencia de la familia de los Claramunt, así como la baronía de Odena?', Capellades o Igualada. Pero no sólo estos conjuntos documentales han sido objeto de una revisión, sino que hemos consultado otras fuentes impresas donde aparecen de manera esporádica referencias a

4. RUIZ-DOMENEC, J.E. (1986), „Transformación y olvido: sobre la familia en el área mediterránea de ínfluencia catalana entre 1170-1320n. Saggi e Documenti VIf, p. 99-134. Civico Istituto Colombiano. Studi e testi. Genova.

5. PONT, M. (1987). Bancelona al segle xiii: Espai de ciutadaria. Universitat Autònoma de Barcelona.

6. AURFIL, M. (1995). Les noces du comte. Marriage et pourvoir en Catalogne (785-1213). París: Publicarions de la Sorbone.

7. Ruus, J. (1946-47). Carrulario de Sant Cugat del Valles. Barcelona: CSIC, vol. II y III.

8. MAS, J. (1914-1915), "Rubrica dels a Libri Antiquitatum de la Seu de Barcelonan. Notes bistòriques del bisbat de Barcelona, vol. 9-12. Barcelona.

9. Álvarez Márquez, M.C. (1990). La baronia de la Conca d'Ódena. Barcelona: Fundació Noguera. 
miembros de la familia Canals, cabe señalar el fondo del archivo de Santa Anna $^{10}$, la colección diplomática del monasterio de Solsona ${ }^{11}$, y la documentación de Santes Creus ${ }^{12}$ y Poblet ${ }^{13}$.

El miembro familiar que tenemos documentado más antiguo corresponde a Ramón Guillem de Canals, el cual aparece como testigo en la donación que hace el clérigo Guillem de unas tierras al monasterio de Sant Cugat en el ańo $1076^{14}$. El linaje está claramente dividido en varios segmentos, diferenciados no sólo por las tierras fértiles que poseen, sino sobretodo por los lazos familiares y las estrategias de parentesco que establecen con otros grupos familiares, ya sean seńores o vasallos.

\section{Segmento A}

Pere Guillem de Canals, del cual desconocemos quien es su mujer, es el iniciador de este segmento; su hijo mayor es Bertrán de Canals, el personaje central y el más importante. Este segmento está emparentado con los Claramunt, de los cuales reciben y, a la vez, dan mujeres. No podemos asegurar que el sistema de parentesco entre los Canals y los Claramunt sea simétrico $^{15}$, pero esta falta de evidencia puede estar motivada por los vacios documentales que no permiten conocer toda la estructura familiar. En la generación de Bertran, su hermano Berenguer de Canals recibe en matrimonio a la hija de Bertran de Claramunt, llamada María. Es en la siguiente generación cuando Bertran dona a su hija Adelaida en matrimonio con Pere de Claramunt, cerrándose de este modo el aparente intercambio directo. En este caso, la falta de documentación nos vuelve a ocultar la estructura familiar. Si se cumplen las normas de parentesco feudal, a tenor de la documentación consultada, hemos de pensar que Bertrán de Canals estaría casado con la hermana de Berenguer de Claramunt e hija de Bernat Guillem de Claramunt, de ese modo la estructura feudal se cumpliría perfectamente.

El personaje central de este segmento, Bertran, es el señor de la casa y fortaleza de Canals el cual jura fidelidad a Ramón Berenguer IV, conde de Barcelon $\mathrm{a}^{16}$, aunque posee otras propiedades laterales en poblaciones del Vallès

10. Alturo Perucho, J. (1985). L'Anxiu antic de Santa Anna de Barcelona del 942 al 1200. Barcelona: Fundació Noguera.

11. ВАCH, A. (1987). Col-lecció diplomàtica del monestir de Santa Maria de Solsona: El Penedès $i$ altres llocs del comtat de Barcelona (segles $X-X V$ ). Barcelona: Departament de Cultura de la Generalitat de Catalunya.

12. Udina Martorfil, F. (1947). El "Llibre Blanch" de Sanites Creus. Cartulario del siglo XII. Barcelona: CSIC.

13. Altisent, A. (1993). Diplomatari de Santa Maria de Poblet, Volum L. Anys 960-1177. Barcelona: Abadia de Poblet. Departament de Cultura de la Generalitat de Catalunya.

14. Rrus, ]. op. cic, vol, n. 687.

15. RUIZ-DOMENEC, J.E. (1985). L'estructura feudal. Barcelona: Edicions del Mall, p. 26.

16. ACA Cancillería. Pergaminos. Ramón Berenguer TV. Carp. 40. N. 335. 


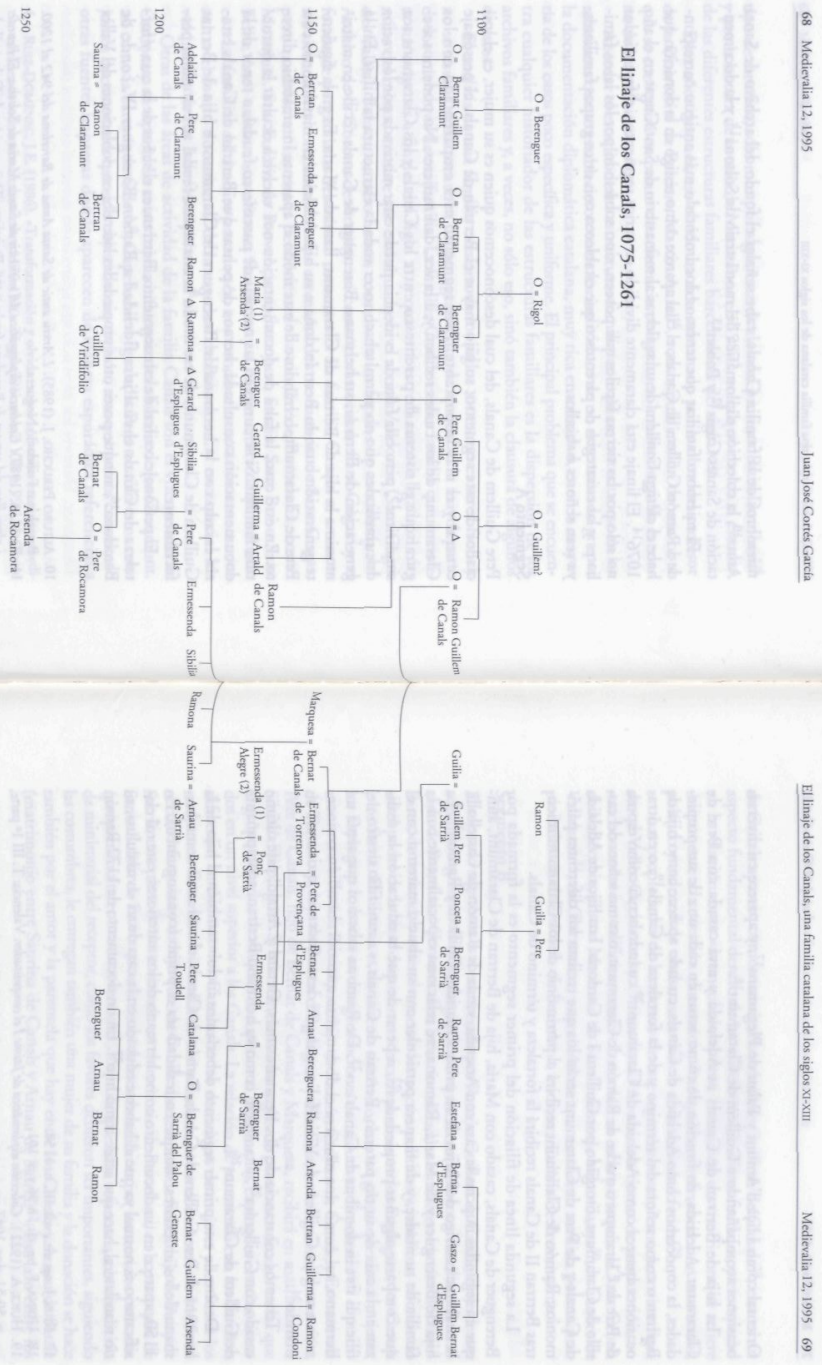


Oriental como Lliçà d'Amunt $y$ Palau de Plegamans ${ }^{17}$, $y$ aparece en diversas ocasiones acompañando a Guillem de Claramunt ${ }^{18}$.

La hija de Bertran de Canals es Adelaida y está casada con Pere de Claramunt. Adelaida, en función de cómo actua en cada una de sus propiedades, la conocemos como Adelaida de Canals, cuando aparece como hija de Bertran o como señora del término y de la fortaleza de Canals ${ }^{19}$; o en otras ocasiones aparece como Adelaida de Claramunt ${ }^{20}$ cuando actua como esposa de Pere de Claramunt o madre de Ramón de Claramunt, o como señora del castillo de Claramunt, otorgado por Guillem I de Cardona. Los hijos de Adelaida de Canals y de Pere de Claramunt serán los que reciban los diferentes patrimonios; Ramón de Claramunt recibirá el patrimonio de los Claramunt mientras Bertran II de Canals recibirá la fortaleza y término de Canals.

La segunda línea de filiación del primer segmento es la formada por Berenguer de Canals, casado con María, hija de Bertran de Claramunt, aunque en segundas nupcias se casa con Arsenda, viuda de Ramón de Castellollí, la cual trae consigo dos hijos de su primer marido, Guillem y Ramón ${ }^{21}$. La hija de Berenguer y de María, Ramona, se relaciona especialmente con la familia de su madre, y de manera particular con su abuelo materno con el que comparte algunas propiedades 22 , a pesar de que la educación la realizan en la casa de su tío paterno, Bertran de Canals, "... uni filio uestro uel filie qui stet in domibus de Canals.... ${ }^{23}$. De Ramona sabemos que tenía un hermano, tal como nos muestra el documento anterior; también conocemos a su hijo Guillem de Viridifolio, aunque desconocemos quien era su marida ${ }^{24}$.

Tenemos constancia de dos hermanos más, Gerard y Artald, éste último casado con Guillerma ${ }^{25}$, y también, como su hermano Bertran, acompañante de Guillem de Claramunt ${ }^{26}$.

Dentro de este primer segmento deberíamos incluir también al hijo de la hermana de Pere Guillem de Canals, Ramón de Canals, el cual actua como hermano de los anteriores, aunque en realidad sea el primo (consanguineo). En 1150 , aparece en un documento como hermano de los anteriores; este rol clasificatorio es normal ya que al haberse educado en la casa de su kavunculus", su tío matrilateral, hace que actue como hijo ${ }^{27}$. En un documento de 1172 Ramón

17. Ruus, J. op. cit., vol. III, n. 1158.

18. Udine, F. op. cit, n 96 y n. 101.

19. Hulcr, A. (1922). Colección diplomdxica de Jaime I el conquistador. Valencia: T. III 1a parte, p. 50-51, doc. 1047.

20. RiUS, J. op. cit., vol. III, n० 1317, 1326, 1367, 1388. Álvarez, M.C. op. cit., n. 61.

21. ACA Cancillería. Pergaminos. Ramón Berenguer IV n. 327.

22. Libri Antiquitatum vol. IV $f, 6$ doc. 18.

23. BACH, A. op. cit., doc. 47, p. 86.

24. ACA Cancillería. Pergaminos. Alfonso I. Carp. 56 Perg. 723.

25. BACH, A. op. cit., doc. 65, p. 103.

26. UDINA, F, op. cit., doc. 96.

27. Libri Antiquitatum vol. If. 
de Canals aparece como "nutricatus» de Pere Guillem de Canals ${ }^{28}$, este es un aspecto fundamental dentro de las relaciones familiares feudales, $y$ en especial en la relación entre "avunculus-nepoten, la función de "nutrir" no se refiere únicamente a la cuestión alimenticia, sinó que hace referencia a un acto social, político y cultural de vital trascendencia en la sociedad feudal ${ }^{29}$.

Las propiedades de las tierras de este segmento están estrechamente ligadas al Vallès Occidental y Oriental y a l'Anoia; son tierras de producción, en muchos casos con edificios, como el mas Aleran en la parroquia de Sant Cebrià de Valldoreix, el mas Materino de Sant Feliuet de Vilamilanys ${ }^{30}$, la quadra de Valldaura ${ }^{31}$, en Claramunt, y también aunque en menor medida poseen propiedades en el territorio de Barcelona, en Santa Eulàlia de Provençana.

\section{Segmento B}

El segundo segmento es el encabezado por Ramón Guillem de Canals; el eje de este segundo segmento es la estrategia de parentesco con diferentes familias del territorio de Barcelona. Con una clara intencionalidad, se establecen los vínculos familiares, de amistad, y extensivamente los pactos políticos y jurídicos, reforzando asi el poder de la clase dominante a la cual pertenecen los Esplugues, los Canals y los Sarrià. El sistema es un sistema simétrico, hay un grupo que dona mujeres; los Esplugues lo hacen en dos generaciones consecutivas, la primera en el matrimonio entre Pere de Provençana, hijo de Ramón Guillem de Canals, y Ermessenda de Torrenova, hija de Bernat d'Esplugues y Estefana; en la siguiente generación, Pere de Canals, hijo de Bernat de Canals y Marquesa, recibirá en matrimonio a Sibilia d'Esplugues. Si nos atenemos a las reglas de parentesco feudal, en las que el grupo donador de mujeres es superior al receptor, los Esplugues estarían situados en un nivel superior a los Canals. La relación de parentesco con los Sarrià es diferente; en este caso los Canals son los donadores de mujeres y los Sarrià los receptores. Esta relación vasallática está plasmada en un documento de 1195, en el cual Marquesa y su hijo Pere de Canals dan a Arnau de Sarrià, hijo de Ponç de Sarrià, una pieza de tierra situada en el territorio de Barcelona, en la parroquia de Santa Eulalia de Provençana; la causa de esta donación es por los servicios prestados (propter multa et maxima servicia), fórmula que hace referencia a la condición de ministerial del receptor, como los favores debieron ser importantes, siguiendo las costumbres, le entregan también una mujer de su familia y la donación se hace también por el amor y la parentela que hay entre los Canals y Arnau de Sarrià (matrimonio entre Saurina de Canals y Arnau de Sarrià) ${ }^{32}$. Ese lazo entre los

28. Libri Antiquitatum vol, 1 f. 320 doc. 897.

29. RUtZ-DOMENEC, J.E. (1993), «Structures de parenté et rapports de production en Catalogne au XII sièclen. Productions pourvoir et parenté dans le monde méditerranéen de Sumer d̀ nos jours. París: Libr, Oruentaliste Paul Geuthner. Vol. II. p. 187-188.

30. Rrus, J. op. cit, vol. III, doc. 1317.

31. Ver nota 18.

32. Libri Antiquitatum vol. If 339 doc. 937. 
Canals y los Sarrià, también queda marcado por la relación económica que se establece entre las dos familias: los Sarrià compran tierras a los Canals ${ }^{33}$, o las reciben en donación ${ }^{34}$ y también reciben préstamos ${ }^{35}$.

Bernat de Canals es el jefe de este segmento, aparece en numerosas ocasiones acompañando a los Claramunt ${ }^{36}$, a su primo Bertran de Canals ${ }^{37}$, compartiendo propiedades con Bertran ${ }^{38}$, o como testigo real ${ }^{39}$.

El personaje más importante de este segundo segmento es Pere de Canals, el cual actua, la mayoría de las veces, acompañando a su madre Marquesa. Pere participó en la conquista y reparto de Mallorca ${ }^{40}$. Las propiedades de Pere están concentradas en el condado de Barcelona, en la zona cercana al castillo de los Canals y en Santa Eulalia de Provençana. Pere es el segundo miembro de este segmento que emparenta con los Esplugues, $y$ lo hace con Sibilia ${ }^{41}$.

El segundo grupo filiativo de este segundo segmento es el de Pere de Provençana, casado con Ermessenda de Torrenova, o d'Esplugues; es la primera generación que recibe mujeres del grupo superior, y además adopta el antropónimo del lugar donde tienen la mayor concentración de tierras fértiles.

Desde el campo de la microhistoria, a través del análisis de una familia feudal catalana, de sus costumbres de parentesco y de su estrategia de alianzas hemos querido aproximarnos al estudio de las estructuras familiares catalanas, y en especial a las estrategias matrimoniales entre la clase dominante del territorio de Barcelona. Es en el siglo XII cuando aparece ese complicado sistema de alianzas matrimoniales, poco estudiado y difícil de seguir por la dispersión documental, $y$ también por la falta de edición de textos. A partir de los años 50 del siglo XII se produce una monopolización de las tierras fértiles, que serán moneda de cambio y desde finales del siglo Xn las tierras servirán para dotar a las hijas para el buen matrimonio, la dote de las hijas era un auténtico suplicio para toda la familia. En 1188 encontramos el caso de Catalana, la hija de Pere de Provençana y Ermessenda de Torrenova ${ }^{42}$, a la cual dotan con todos los alodios que la familia tiene en la parroquia de Sant Boi y las casas, tierras, viñas y árboles frutales que tienen en Santa Eulàlia de Provençana. Se hace necesario el ampliar los análisis microhistóricos de estructuras familiares para de esa manera romper con las decimonónicas genealogías que se basan exclusivamente en la filiación, ignorando, por completo, el equilibrio entre filiación y

33. Libri Antiquitatum vol. If. 330 d. 939.

34. Idem 31.

35. Libri Antiquitatum vol. If. doc. 938.

36. RIUs, J. op. cit., vol. III, n 1159.

37. RuUs, J. op. cit., vol. III, n 1158

38. Libri Antiquitatum vol. IV f. 7 doc. 21.

39. UDINA, F. op. cit., n 133. ALTISENT, A. op. cit, n. 318.

40. Codex català del Llibre del repartiment de Mallorca. f. 21r. alqueria Abenresc iii jo. es den G, de Vilaragut, e den P. de Canalsn.

41. Idem. 32.

42. Arxiu Diocesà de Barcelona. Carp. 3A perg. 183. Fons Santa Anna. Alturo, J. op. cit., vol. III, n 537. 
alianza. Los resultados aquí presentados no son definitivos, es la primera aproximación al linaje de los Canals y a sus estrategias de parentesco, dificultados por el silencio de la documentación, en especial en lo que hace referencia a la identificación de las mujeres.

\section{Apéndice documental}

\section{1160 , mayo, 21 .}

Juramento de fidelidad de Bertran de Canals, señor del castillo de Canals a Ramón Berenguer IV:

A.: ACA Cancillería. Pergaminos Ramón Berenguer IV, n. 335.

a.: Bofarull, P.: Colección de documentos inéditos del ACA, vol, IV, p. 288-289.

b.: Rosell, M. Liber Feudaram Maior. Vol. I, p. 390.

luro ego Bertrandus de Canals tibi, domno Raimundo Berengarii, Barchinonensium comiti et marchioni et Aragonensium principi, quod ab ista hora in antea non exeat tibi ullum malum neque tuo honori neque tuis hominibus de ipsa domo uel fortitudine de Canals. Et si forte contigerit fieri, redigiram illud tibi uel tuis infra XXX dies quibus amonitus uel inquisitus fuero per te uel per tuos; et me uideri uel amoneri non uetabo. Et conuenio tenere et atenere ipsam scripturam et que in ea continentur, que est inter Sanctum Cucuphatem et me per laudamentum amicorum meorum facta sine engan. Per Deum et hec sancta.

Acrum et hoc XII kalendas iunii annoXXIII regni regis Ledouici iunioris.

Sig+num Bertrandi de Canals. Sig+num Guillelmi de Castro Vetulo. Sig+num Raimundi de Subirats. Sig+num Raimundi Bermundi de Castro Episcopali. Scripta libens ista, Petrus confirmo, sacrista. Bernardus, leuita, qui hoc scripsit die et anno prefixo. Facto hos sacramento super altare Sancti lusti, martiris.

\section{1195, Marzo, 22.}

Ramona de Canals, hija de Berenguer de Canals, y su hijo Guillem de Viridifolio, venden al Temple, un alodio sito en Montjuic, territorio de Barcelona, por 180 sueldos barceloneses.

A.: ACA Cancillería. Pergaminos Alfonso I. Carp. 56, n. 723.

Notum sit cunctis quod Ego Raimunda qui fui filia Berengarii de Canalibus et filius meus Guillelmus de Virifolio, uendimus Deo et Milicie Templi et tibi Guillelmo de Cerdaniola, Perceptoris et habibus ipsius domus, alodium meum propium cum tallis et oliuariis quod per uocem genitorum meorum habeo in Monte ludaico sicut terminatur ab oriente in alodio cannonice et iudeorum, a meridie in alodio eiusdem Milicie Templi et canonice, ab occiduo in alodio Sancti Pauli, a circi similiter, quantum ab his terminis concluditur et terminantur hec omnia cum introhitibus et exitibus suis, uendimus Deo et domui Milicie et fratribus suis et ut melius dici uel intelligi potest ad utilitatem eiusdem domus de nostro iure in ius et dominium suum tradimus ad quicqid ibi uel exinde fratres milicic templi facere uolueritit sine uinculo ullius hominus uel femine et sine ullo retentu accepimus quoque pro hac uenditione de bonis ipsius domus CLXXX solidus denariorum Barchinone et nichil apud domum Militie Templi remansit in debito et est manifestatum. Siquis hoc fregerit, supradicta in duplo componat, et in super maneat firmum. 
Actum est hoc XI kalendas aprilis anno Domini $\mathrm{M}^{\circ} \mathrm{C} \mathrm{X}^{\circ} \mathrm{C}^{\circ} \mathrm{V} \circ$

Sig+num Raimunde. Sig+num Guillelmi de Viridifolio, filii eius qui hoc laudamus et firmamus. Sig+num Petri Suaris. Sig+num Raimundi de Sema. Sig+num Raimundi de Portu.

Sig+num Petri de Corron, scriptoris qui hoc scripsit die et anno quo supra.

\section{1243 , septiembre, 13 .}

Jaime I concede la jurisdicción del castillo y término de Canals y la cuadra de Vall de Lors a Adelaida de Canals, viuda de Pedro de Claramunt.

A.: Original perdido. (Antigua signatura. ACA: Hacienda, Monacales. Sant Cugat. Pergaminos. Carp. 4, n. 1391).

a.: Huicr, A. (1992). Colección diplomática de Jaime I el Conquistador. T. III. $1^{\text {a }}$ parte. Valencia, p. 50-51, doc. 1047.

b.: Huici, A.; CaBAnES, M.D. (1976). Documentos de Jaime I de Aragón. vol. II 1237-1250. Textos Medievales 50. Valencia, p. 165-166, doc. 379.

Noverint Universi quod nos lacobus, Dei gratia rex Aragonum, Maiaricarum et Valencie, comes Barchinone et Urgelli et dominus Montispesulani, recognocimus et concedimus yobis Adeledi de Canals, uxori quondam Petri de Claramonte, quod habetis iurisdiccionem in fortitudine et villa de Canalibus et terminis suis et in quadra de Vall de Lors et quod vos et antecessores vestri consueristis et potestis de iure vestro copere et captos tenere omnes delinquentes et maleficium comitentes palam vel occulte in locis predictis, pro maleficiis tantum que ibi comiserint et punire ipsos in pecunia, rebus et personis eorum, exceptis morte et mutilacione membrorum. Verum tamen illos, quos ceperitis seu captos tenebitis, qui censeantur mereri mortem seu mutilacionem membrorum debetis tradere vicario nostro. Quare dicimus et mandamus firmiter et expresse procuratoribus, vicariis, baiulis et universis officialibus et subditis nostris, presentibus et futuris, quod predicta iurisdiccione vos et vestros perpetuo in locis predictis et terminis suis libere ut permitant et non contraveniant nec aliquem contravenire permitant aliqua racione. Si quis autem, contra aliquod de predictis, que vobis et vestris concedimus venire presumpserit, iram et indignacionem nostram et penan quingentorum morabetinorum se noverit incunisse et nichilominus predicta permaneant et sint in suo robore perpetuo et valore, quoniam constat nobis quod predicta iurisdiccione ibidem a longis temporibus citra usa estis.

Datum Barchinone, idus septembris, anno Domini Mo. CCo. XI ${ }^{\circ}$. III.

Signum (signo) Iacobi Dei gratia regis Aragonum, Maioricarum et Valencie, comitis Barchinone et Urgelli et domini Montispesulani.

Testes huius rei: P[etrus] de Montecathano; G[uillelmus] d'Entense; G [uillelmus] de Cervilione; G[uillelmus] de Sancto Vicencio; A[rnaldus] de Verneto. 